\title{
Current Mode Schmitt Trigger Circuit Design Using Only Single CCCDTA
}

\author{
Rupam Das, Hemanshu Kumar, Anup Kr.Giri and Anish Prasad
}

\begin{abstract}
Here a simple current mode Schmitt trigger circuit is designed using a single current controlled current differencing transconductance amplifier (CCCDTA). The presented circuit is proposed here by single CCCDTA without utilizing any passive components. A supply voltage of $\pm 1 v$ and $0.35 \mu \mathrm{m}$ TSMC CMOS model parameter is used for the design of Schmitt trigger. The circuit presented in this paper operates at a low voltage and low frequency. The proposed circuit is tested in PSPICE platform and it meet with the theoretical prediction.

Keywords

Analog signal processing;

Current Mode Schmitt Trigger circuit;

Monostable multivibrator;

Schmitt Trigger circuit

Triangular waveform.
\end{abstract}

\section{INTRODUCTION}

The Schmitt Trigger circuit was first proposed or invented by O.H. Schmitt in the year of 1938 [1]. This circuit has an interesting property related to converting varying voltage into a steady logical signal basically used in analogas well as digital domain. Schmitt Trigger circuit can be used in various field such as function generator [2], monostable multivibrator [3], [4] pulse width modulator, [5] [6] [7] and square waveform generator [8], [9], [10].

The current mode signal processing techniques was first introduced by Barrie Gilbert. In current mode circuits Currents are the operating parameter of the individual circuit elements must be interact by in terms of current instead of voltage. In current mode circuits information is basically presented as branch currents in the circuit diagram. As compare to operational amplifier based circuits recently there are various signal processing is supported by the building blocks are current Conveyor (CC) [11], Differential difference current conveyor (DDCC) [12], Differential voltage current conveyor (DVCC) [13], current controlled differential difference current conveyor transconductance amplifier (CCDDCCTA) [14]. A new building block is introduced named Current Controlled Current Differencing Transconductance Amplifier (CCCDTA) [15]. Parasitic resistances of the proposed circuit presented at two input port may be regulated by means of input bias current in CCCDTA building block so it does not require any resistances in practical applications.

Schmitt trigger circuits using different voltage and current mode devices are present in the literature. Opamp is used as the basic block and it is designed with three passive components [11], current conveyor based Schmitt trigger circuit using two active building block and four passive components [16], another current conveyor based circuit has large number of passive components [17], Schmitt trigger based on OTRA uses a switch and a floating resistor [18], DVCC based Schmitt trigger uses a single active building block and two passive components [13], In [19] Schmitt trigger circuit is proposed by building block CDTA, in [20] OTA based Schmitt trigger uses maximum components MO-CTTA based Schmitt trigger is designed without using any passive components [21].

Here a new circuit has been introduced using CCCDTA. The very simple it has only one CCCDTA building block without any passive components in the circuit. In this circuit the hysteresis and the amplitude electronically controlled by varying only bias current. The PSPICE simulation is also shown which satisfies the theoretical analysis. This circuit can be used in various applications such as triangular/ square wave generators, relaxation oscillator etc.

The paper is organised as follows: in section 2 , CCCDTA basic concepts is given, in section 3, the operation of the proposed circuit is discussed, section 4 refers the PSPICE simulated results and the previous 
work comparison with the proposed work, conclusion are given in section 5 .

\section{CCCDTA Fundamental}

The CCCDTA building block (Fig. 1), and its equivalent circuit diagram (Fig. 2) and CMOS based circuit diagram (Fig. 3) is shown here.

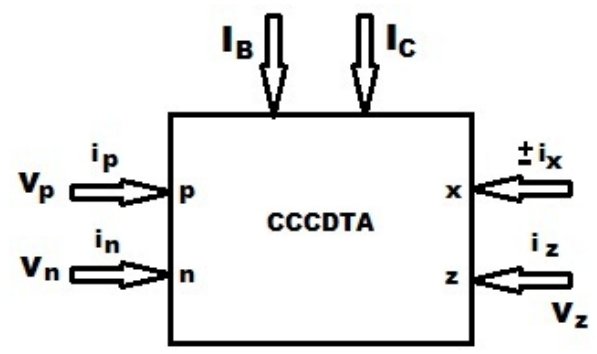

Fig. 1. Block diagram of CCCDTA

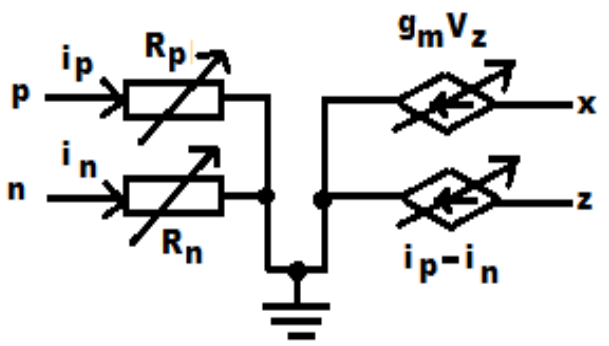

Fig. 2. Equivalent circuit diagram of CCCDTA

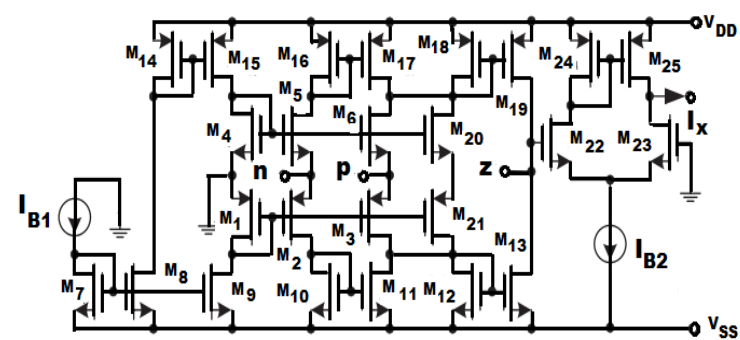

Fig.3. CMOS circuit diagram of CCCDTA

All the properties of CCCDTA and CDTA are similar other than input voltages of CCCDTA is not ground voltage or zero and it has input resistances $R_{P}$ and $R_{n}$ at the both $p$ and $n$ terminals. Bias current $I_{B 1}$ control these resistances. The port relationship can be represented by the following matrix:

$$
\left[\begin{array}{c}
V_{p} \\
V_{n} \\
I_{z} \\
I_{x}
\end{array}\right]=\left[\begin{array}{cccc}
R_{p} & 0 & 0 & 0 \\
0 & R_{n} & 0 & 0 \\
1 & -1 & 0 & 0 \\
0 & 0 & 0 & \pm g_{m}
\end{array}\right]\left[\begin{array}{c}
I_{p} \\
I_{n} \\
V_{x} \\
V_{z}
\end{array}\right]
$$

The ideal conditions are given as:

$$
\mathrm{V}_{\mathrm{p}}=\mathrm{I}_{\mathrm{p}} \mathrm{R}_{\mathrm{p}}, \mathrm{V}_{\mathrm{n}}=\mathrm{I}_{\mathrm{n}} \mathrm{R}_{\mathrm{n}}, \mathrm{I}_{\mathrm{z}}=\mathrm{I}_{\mathrm{p}}-\mathrm{I}_{\mathrm{n}}, \mathrm{I}_{\mathrm{x}}= \pm \mathrm{g}_{\mathrm{m}} \mathrm{V}_{\mathrm{z}}
$$

From Fig the $\mathrm{p}$ and $\mathrm{n}$ are input terminal $\mathrm{z}$ is an auxiliary terminal and $\mathrm{x}$ is the output terminal and $\mathrm{g}_{\mathrm{m}}$ is the transconductance of the CCCDTA. Here the outgoing current is the difference between the two input current but different direction. The product of transconductance $\left(\mathrm{g}_{\mathrm{m}}\right)$ and the $\mathrm{z}$ terminals voltage gives their magnitude.

\section{PROPOSED CIRCUIT}

By using a single CCCDTA and without using any passive components the proposed Schmitt trigger circuit is designed and it is shown in Fig.3. The proposed circuit is operated as follows: when a triangular or sign waveform is applied to terminal $n$ then input will change from + Iin to -Iin then the output will change from $-\mathrm{I}_{\mathrm{B} 2}$ to $\mathrm{I}_{\mathrm{B} 2}$. The output current remains at the state $-\mathrm{I}_{\mathrm{B} 2}$ until input Iin is greater than or equal to $-\mathrm{I}_{\mathrm{B} 2}$, this is called upper threshold point (UTP).

When input current will change from -Iin to Iin then output will be changing from $+\mathrm{I}_{\mathrm{B} 2}$ to $-\mathrm{I}_{\mathrm{B} 2}$ until the input is less than or equal to $\mathrm{I}_{\mathrm{B} 2}$ and this point is called lower threshold point (LTP).

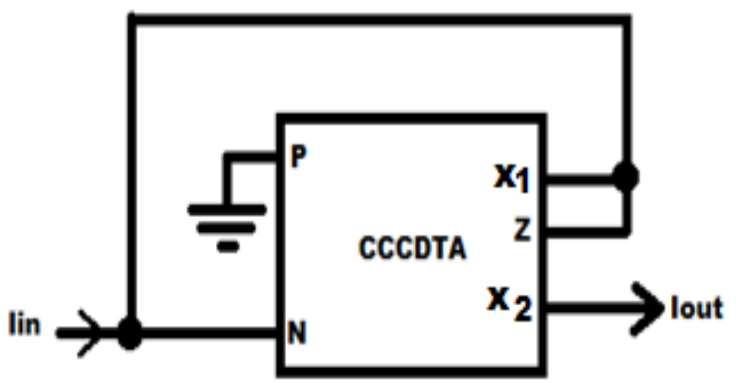

Fig. 4. Proposed CCCDTA based Schmitt Trigger

The transfer characteristics is shown in Fig.4. The proposed Schmitt trigger can be written as :

$\mathrm{I}_{0}=-\mathrm{I}_{\mathrm{B} 2}$ for $\mathrm{I}_{\mathrm{in}} \geq \mathrm{I}_{\mathrm{X} 2}$

$\mathrm{I}_{\mathrm{B} 2}$ for Iin $\leq \mathrm{I}_{\mathrm{X} 2}$

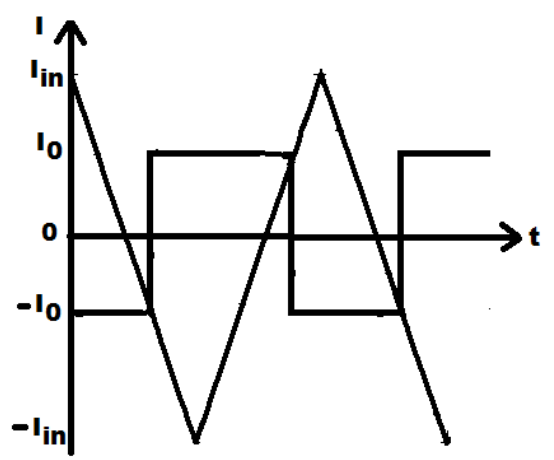

Fig. 5. Input/output waveform of the proposed Schmitt Trigger circuit

\section{SIMULATION RESULTS}

proposed circuit is simulated using $0.35 \mu \mathrm{m}$ TSMC technology process parameter. In Table 1 the aspect ratio of CCCDTA CMOS transistors are given. Here

Rupam Das, Hemanshu Kumar, Anup Kr.Giri and Anish Prasad, "Current Mode Schmitt Trigger Circuit Design Using Only Single CCCDTA", International Journal of Advanced Engineering and Management, Vol. 2, No. 9, pp. 219-222, 2017. DOI: https://doi.org/10.24999/IJOAEM/02090049 
supply voltage of $\pm 1 \mathrm{v}$ and bias current $\mathrm{I}_{\mathrm{B} 1}=50 \mathrm{uA}$ and $I_{B 2}=60 u A$ are taken for the design of the circuit. For low voltage and low power applications the proposed circuit is suitable. A triangular waveform of $\pm 50 \mathrm{uA}$ amplitude and $10 \mathrm{KHz}$ waveform is applied to the circuit and the corresponding input and output waveform is shown in Fig.6. A sine waveform of $\pm 50 \mathrm{uA}$ amplitude and $1 \mathrm{KHz}$ waveform is applied to the circuit and the corresponding input and output waveform is shown in Fig.7. The hysteresis curve of the circuit is also shown in Fig.8.

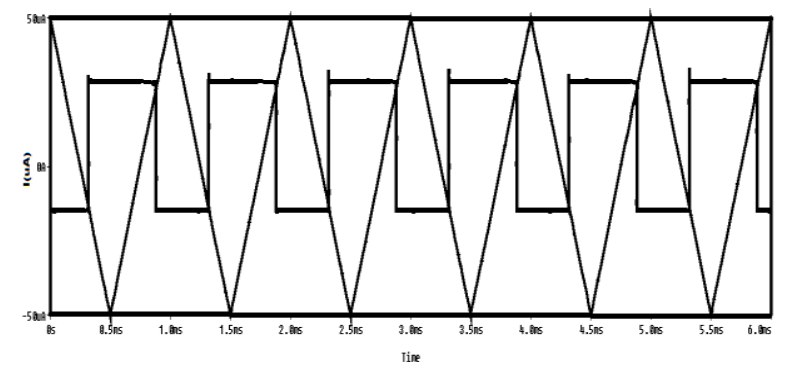

Fig. 6. Simulated input/output waveform of the proposed Schmitt Trigger circuit

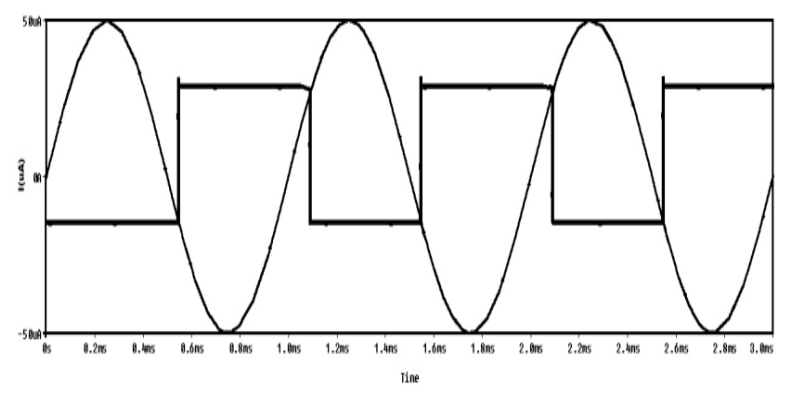

Fig. 7. Simulated input/output waveform of the proposed Schmitt Trigger circuit

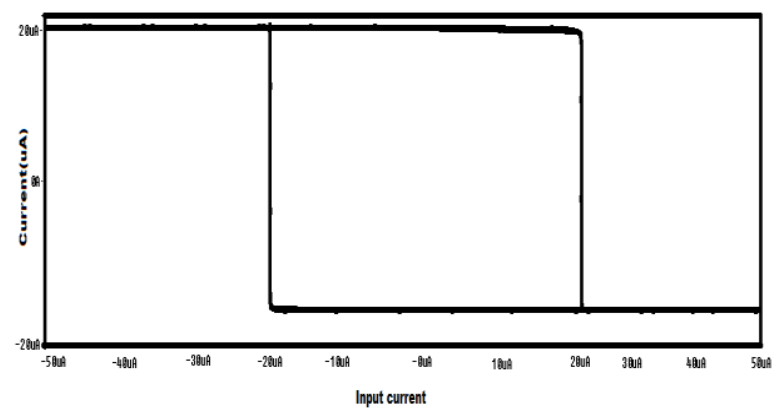

Fig.8. Hysteresis curve of the proposed circuit

Table 2: Comparison of the previously published works

\begin{tabular}{|c|c|c|c|c|c|c|}
\hline $\begin{array}{c}\text { Ref } \\
\text { no }\end{array}$ & $\overline{\mathrm{ABB}}$ & $\begin{array}{c}\text { Technol } \\
\text { ogy } \\
\text { used }\end{array}$ & $\begin{array}{c}\text { BJT/M } \\
\text { OS } \\
\text { based } \\
\text { design }\end{array}$ & $\begin{array}{c}\text { No } \\
\text { of } \\
\text { acti } \\
\text { ve } \\
\text { bloc } \\
\text { k }\end{array}$ & $\begin{array}{l}\text { No of } \\
\text { passive } \\
\text { compon } \\
\text { ents }\end{array}$ & $\begin{array}{c}\text { Supp } \\
\text { ly } \\
\text { volta } \\
\text { ge }\end{array}$ \\
\hline 16 & $\begin{array}{c}\text { OPAM } \\
\text { P }\end{array}$ & - & $\mathrm{IC}$ & 1 & 3 & $\begin{array}{c} \pm 12 \\
\mathrm{~V}\end{array}$ \\
\hline 17 & $\mathrm{CCII}$ & AD844 & IC & 2 & 4 & $\pm 6 \mathrm{~V}$ \\
\hline 18 & CCII & $\begin{array}{c}\text { QN/QP- } \\
2222\end{array}$ & $\mathrm{BJT}$ & 1 & 3 & $\pm 5 \mathrm{~V}$ \\
\hline
\end{tabular}

\begin{tabular}{|c|c|c|c|c|c|c|}
\hline 19 & OTRA & $\begin{array}{c}\text { AD844/ } \\
\text { AN }\end{array}$ & MOS & 1 & 1 & $\begin{array}{c} \pm 10 \\
\text { V }\end{array}$ \\
\hline 20 & DVCC & $.25 \mu \mathrm{m}$ & MOS & 1 & 2 & $\begin{array}{c} \pm 1.2 \\
5 \mathrm{~V}\end{array}$ \\
\hline 21 & CDTA & $.25 \mu \mathrm{m}$ & MOS & 1 & 2 & - \\
\hline 22 & OTA & $\begin{array}{c}\text { LM136 } \\
00\end{array}$ & BJT & 2 & 2 & $\begin{array}{c} \pm 10 \\
\mathrm{~V}\end{array}$ \\
\hline 23 & CDTA & $\begin{array}{c}0.25 \mu \mathrm{m} \\
\text { MIETE } \\
\text { C }\end{array}$ & MOS & 1 & 2 & - \\
\hline $\begin{array}{c}\text { Propo } \\
\text { sed } \\
\text { CKT }\end{array}$ & $\begin{array}{c}\text { CCCD } \\
\text { TA }\end{array}$ & $\begin{array}{c}0.35 \mu \mathrm{m} \\
\text { TSMC }\end{array}$ & MOS & 1 & 0 & $\pm 1 \mathrm{~V}$ \\
\hline
\end{tabular}

\section{CONCLUSION}

A single CCCDTA building block is used to design the Schmitt trigger. No passive component is used in the proposed circuit diagram which is easy implementation of monolithic integration. $\pm 1 \mathrm{v}$ supply voltage and $.35 \mu \mathrm{m}$ TSMC process parameter is used in the proposed circuit. Hysteresis curve and transient response of the proposed circuit are presented in this paper. The proposed circuit has various applications like analog signal processing, instrumentation and measurements.

\section{REFERENCES}

[1] Schmitt, O. H. (1938). A thermionic trigger. Journal of Scientific Instruments, 15(1), 24-26.

[2] Chung, W. S., Kim, H., Cha, H. W., \& Kim, H. J. (2005). Triangular/square-wave generator with independently controllable frequency and amplitude. IEEE transactions on instrumentation and measurement, 54(1), 105-109.

[3] Chung, W. S., Cha, H. W., \& Kim, H. J. (2002). Current-controllable monostable multivibrator using OTAs. IEEE Transactions on Circuits and Systems I: Fundamental Theory and Applications, 49(5), 703-705.

[4] Lo, Y. K., \& Chien, H. C. (2007). Single OTRAbased current-mode monostable multivibrator with two triggering modes and a reduced recovery time. IET Circuits, Devices \& Systems, 1(3), 257-261.

[5] Kim, H., Kim, H. J., \& Chung, W. S. (2007). Pulsewidth modulation circuits using CMOS OTAs. IEEE Transactions on Circuits and Systems I: Regular Papers, 54(9), 1869-1878.

[6] Siripruchyanun, M., \& Wardkein, P. (2003). A fully independently adjustable, integrable simple current controlled oscillator and derivative PWM signal generator. IEICE transactions on

Rupam Das, Hemanshu Kumar, Anup Kr.Giri and Anish Prasad, "Current Mode Schmitt Trigger Circuit Design Using Only Single CCCDTA”, International Journal of Advanced Engineering and Management, Vol. 2, No. 9, pp. 219-222, 2017. DOI: https://doi.org/10.24999/IJOAEM/02090049 
fundamentals of electronics, communications and computer sciences, 86(12), 3119-3126.

[7] Srinivasulu, A., Rukmini, M. S. S., Musala, S., \& Prasad, S. (2014, September). Pulse width modulator based on second generation current conveyor. In Devices, Circuits and Communications (ICDCCom), 2014 International Conference on (pp. 1-4). IEEE.

[8] Srinivasulu, A. (2009). Current conveyor-based square-wave generator with tunable grounded resistor/capacitor. In Applied Electronics, 2009. AE 2009 (pp. 233-236). IEEE.

[9] Srinivasulu, A. (2011). A novel current conveyor-based Schmitt trigger and its application as a relaxation oscillator. International Journal of Circuit Theory and Applications, 39(6), 679-686.

[10] Kar, S. K., \& Sen, S. (2011). Tunable squarewave generator for integrated sensor applications. IEEE Transactions on Instrumentation and Measurement, 60(10), 3369-3375.

[11] Network, A. O., \& Cherry, E. (1970). A secondgeneration current conveyor and its applications. IEEE Transactions on circuit theory, 17(10), 132-4.

[12] Chiu, W., Liu, S. I., Tsao, H. W., \& Chen, J. J. (1996). CMOS differential difference current conveyors and their applications. IEE Proceedings-Circuits, Devices and Systems, 143(2), 91-96.

[13] Misurec, J., \& Koton, J. (2012). Schmitt trigger with controllable hysteresis using current conveyors. International Journal of Advances in Telecommunications, Electrotechnics, Signals and Systems, 1(1), 26-30.

[14] Pandey, N., Kumar, P., \& Choudhary, J. (2013). Current controlled differential difference current conveyor transconductance amplifier and its application as wave active filter. ISRN Electronics, 1-11.

[15] Siripruchyanun, M., \& Jaikla, W. (2008). CMOS current-controlled current differencing transconductance amplifier and applications to analog signal processing. AEU-International Journal of Electronics and Communications, 62(4), 277-287.
[16] Siripruchyanun, M., \& Jaikla, W. (2008). Current controlled current conveyor transconductance amplifier (CCCCTA): a building block for analog signal processing. Electrical Engineering,90(6), 443453.

[17] Diutaldo, G., Palumbo, G., \& Pennisi, S. (1995). A Schmitt trigger by means of a CCII+. International Journal of Circuit Theory and Applications, 23(2), 161-165.

[18] Lo, Y. K., Chien, H. C., \& Chiu, H. J. (2010). Current-input OTRA Schmitt trigger with dual hysteresis modes. International Journal of Circuit Theory and Applications, 38(7), 739-746.

[19] Biolek, D., \& Biolková, V. (2006, September). Current-mode CDTA-based comparators. In The 13th electronic devices and systems 2006 IMAPS CS/SK international conference, EDS (pp. 6-10).

[20] Kim, K., Cha, H. W., \& Chung, W. S. (1997). OTA-R Schmitt trigger with independently controllable threshold and output voltage levels. Electronics letters, 33(13), 1103-1105.

[21] Silapan, P., \& Siripruchyanun, M. (2009, May). A simple current-mode Schmitt trigger employing only single MO-CTTA. In Electrical Engineering/Electronics, Computer, Telecommunications and Information Technology, 2009. ECTI-CON 2009. 6th International Conference on (Vol. 1, pp. 556559). IEEE.

\section{Rupam Das}

Asansol Engineering College, Asansol, India das_rupam@rediffmail.com

\section{Hemanshu Kumar}

Asansol Engineering College, Asansol, India hemanshusani@gmail.com

\section{Anup Kr Giri}

Asansol Engineering College, Asansol, India anupgiri094@gmail.com

\section{Anish Prasad}

Asansol Engineering College, Asansol, India anish8129@gmail.com

Rupam Das, Hemanshu Kumar, Anup Kr.Giri and Anish Prasad, "Current Mode Schmitt Trigger Circuit Design Using Only Single CCCDTA”, International Journal of Advanced Engineering and Management, Vol. 2, No. 9, pp. 219-222, 2017. DOI: https://doi.org/10.24999/IJOAEM/02090049 